\title{
Kitsch dalam Iklan TV Komersial dan Selera Konsumer Indonesia
}

\author{
Wildan Hanif, Yasraf Amir Piliang \\ Fakultas Seni Rupa \& Desain, Institut Teknologi Bandung, \\ Jl. Ganesha 10 Bandung 40135,
}

\begin{abstract}
Commercial TV advertising has a considerable influence on the tastes of consumers. Research on the kitsch-laden TV ads, which are often associated with bad taste, try to answer how is the consumer tastes of the people of Indonesia in 2015. The method used is the method of crossdisciplinary approach to Cultural studies. This study provides a picture of the mass consumer tastes Indonesia as a result of commercial TV ad impressions. By taking samples of "Biji Selasih Serbuk Panas Dalam Bintang Toedjoe" "TV ad, found that the advertisement contained elements of global culture mixed (hybrid) with the local culture and popular myths typical of Indonesia. The results of this study also showed that the tastes of Indonesian people, especially the lower middle class, strongly associated with the character of Indonesian people who have a high artistic instinct, happy to show off, but easily influenced by the culture from the outside, believe in superstitious, and is hypocritical.
\end{abstract}

Keywords: Kitsch, Consumer Tastes, TV ad

\begin{abstract}
ABSTRAK
Iklan TV komersial memiliki hubungan timbal balik dengan selera konsumer. Penelitian mengenai iklan TV bermuatan kitsch, sering dikaitkan dengan selera rendah ini. Hasil penelitian ini mencoba menjawab bagaimana gambaran selera masyarakat konsumer Indonesia pada tahun 2015. Metode yang digunakan adalah metode lintas disiplin dengan pendekatan Cultural studies. Penelitian ini menguraikan gambaran selera massa konsumer Indonesia sebagai dampak dari tayangan iklan TV komersial. Dengan mengambil sampel "Iklan Biji Selasih Serbuk Panas Dalam Bintang Toedjoe", didapati bahwa iklan tersebut mengandung unsur budaya global yang bercampur (hibrid) dengan budaya lokal dan mitos populer khas Indonesia. Hasil penelitian ini juga menunjukkan bahwa selera masyarakat Indonesia, terutama kelas menengah bawah, sangat terkait dengan karakter manusia Indonesia yang memiliki naluri berkesenian yang tinggi, suka pamer, percaya tahayul, mudah dipengaruhi oleh budaya dari luar, dan bersifat hipokrit.
\end{abstract}

Kata kunci : Kitsch, Selera Konsumer, Iklan TV 


\section{PENDAHULUAN}

Karya seni yang otonom, orisinil, subjektif, dan kreatif, adalah kredo dalam wacana seni modern. Iklan, dengan demikian, dalam wacana seni modernisme tidak dianggap sebagai karya seni karena sifatnya yang diproduksi secara massal. Namun dalam wacana estetika postmodern yang diikuti oleh perkembangan teknologi pencitraan yang semakin canggih dalam industri periklanan, juga fakta bahwa disiplin ilmu periklanan telah dipelajari secara resmi dan diakui di akademi/institut seni di Indonesia bahkan di seluruh dunia sebagai fenomena budaya kontemporer yang tidak bisa dilepaskan dari masyarakat konsumer. Iklan, sebagaimana disebutkan oleh Iain Macrury, justru telah menjadi “seni resmi masyarakat kapitalis" (Macrury dalam Hanif: 2015). Iklan bukanlah fine art, yakni jika kita merujuk pada wacana seni zaman modernisme yang menjustifikasi adanya dikotomi seni tinggi/seni rendah.

Fenomena yang terjadi setelah televisi menjadi primadona yang menghiasi rumah penduduk dunia, serta kemampuannya melipatgandakan informasi audio visual secara massif dan massal, membuat televisi dilirik oleh pengiklan dan ditempatkan sebagai alat utama promosi sebuah produk/ media lini atas (above the line). Saat ini Industri periklanan di negara manapun, termasuk di Indonesia tak mungkin berjalan tanpa bantuan televisi. Maka proses reproduksi iklan bermuatan kitsch pada media televisi, dengan menjadikannya sebagai sebuah 'seni massa', adalah fenomena post-modernisme dalam kajian seni rupa dan desain. Iklan TV, sebagai sebuah simulasi tanda- tanda visual, aural, dan verbal, merupakan suatu bentuk pengkodean berbagai tanda yang ditujukan untuk membujuk dan merayu.

Dalam halaman pembuka buku "Ad- vertising" karya Iain Macrury (2002), disebutkan bahwa "Periklanan, jika dilihat sebagai 'seni resmi masyarakat kapitalis', adalah komponen yang semakin dianggap lumrah sebagai karakteristik budaya promosi". Sesuatu yang sudah dianggap lumrah, biasa, remeh, tanpa dikritisi secara intelektual oleh massa, merupakan salah satu ciri ketidaksadaran (unconscious). "Jadi dalam hal ini, pesan tersembunyi (subliminal message) iklan secara umum, dan apalagi iklan yang ditayangkan di TV, bekerja secara halus dan tanpa disadari, masuk dan berakumulasi ke dalam alam bawah sadar penontonnya" (Hanif dkk, 2015).

Periklanan tumbuh amat cepat menjadi industri raksasa. Cara beriklan disesuaikan dengan karakteristik dan kondisi psikis pemirsa yang menjadi target sasaran. Di Amerika, Psikolog dan Asisten Profesor Walter Dill Scott memperkenalkan studi psikologi sebagai unsur penting dalam periklanan dalam The Psychology of Advertising Theory and Practice (1902). Sebagai bagian dari karya-karyanya ia menanyai konsumen tentang reaksi mereka pada berbagai iklan - sebagai awal riset pasar. Dalam majalah periklanan, Printers Ink, ia menyatakan: "pemasang iklan yang berhasil, baik secara pribadi atau melalui agensi periklanan, harus mempelajari psikologi dengan seksama. Dia harus mengerti bagaimana pikiran manusia. Dia harus tahu apa yang tidak diinginkan dan apa yang menarik perhatian orang. Dia harus tahu segala hal tentang jiwa manusia" (Scott:1921).

Kondisi perubahan dunia global akan sangat berpengaruh pada kehidupan sosial budaya di Indonesia. Era televisi swasta dan internet yang sudah sampai ke desa- desa menyebabkan cara berpikir, pola hubungan sosial dan budaya, serta selera estetis masyarakat ikut berubah. Meskipun 
internet telah sampai ke desa- desa, televisi masih menjadi primadona sebagian besar masyarakat Indonesia. Program tayangan televisi swasta yang terutama ditujukan kepada golongan masyarakat ekonomi menengah dan menengah bawah tetap diminati, termasuk iklan iklan TV komersial yang disisipkan di sela- sela tayangan.

Pertanyaan penelitian terkait dengan latar belakang dan fenomena tersebut di atas adalah: Sejauh manakah perubahan kondisi dunia global pada masyarakat konsumer Indonesia? Apakah kondisi tersebut secara radikal dapat mengubah karakter dan selera estetis masyarakat Indonesia?, dan apakah jejak perubahan tersebut dapat ditelusuri melalui fenomena iklan TV, terlebih iklan TV produk murah yang ditujukan untuk kalangan masyarakat pra sejahtera?. Penelitian ini tentu tidak akan sanggup menjawab secara komprehensif mengenai perubahan karakter masyarakat Indonesia pasca reformasi dengan beragam persoalan yang amat kompleks. Penelitian ini lebih difokuskan pada aspek 'selera estetis' massa konsumer sasaran iklan TV komersial bermuatan 'kitsch', yakni mencoba menjawab pertanyaan 'mengapa' dan 'bagaimana' sesungguhnya selera massa konsumer Indonesia dalam kaitannya dengan iklan TV produk komersial.

\section{METODE}

Penelitian ini menggunakan berbagai kajian yang saling terkait satu sama lain. Pertama, Kajian tentang budaya massa dari tokoh Frankfurt School semacam Theodor Adorno untuk menjawab bagaimana sesungguhnya massa konsumer secara tidak kritis mengkonsumsi teks berupa iklan yang disuguhkan oleh industri kapitalisme. Kedua, Kajian kitsch sebagai bagian dari estetika postmodern/ hipersemiotika dari Yasraf Amir Piliang, yang akan dikaitkan dengan filsafat nihilisme dari Nietzche. Ketiga, kajian iklan dengan semiotika komunikasi yang peneliti olah dan kembangkan dari Alex Sobur, Arthur Asa Berger, dan Roland Barthes, terutama untuk menemukan indeks/ indikasi dan mitos dari berbagai adegan visual dan aural dari iklan TV, Keempat, Kajian psikologi iklan dari tokoh- tokoh peneliti periklanan dunia semacam Walter D Scott dan Iain Macrury, yang menegaskan bahwa iklan merupakan 'seni komersial' yang bertujuan untuk menjual produk. Kelima, kajian tentang sifat dan karakteristik Manusia Indonesia dari Mochtar Lubis, yang akan dikaitkan dengan selera konsumer Indonesia.

Melihat banyaknya disiplin ilmu yang akan digunakan untuk membedah iklan TV bermuatan kitsch tersebut dari mulai teori estetika dan filsafat seni, teori komunikasi massa, psikologi iklan, bahkan analisis sosial budaya dalam wacana kritis, maka penelitian ini otomatis bersifat kualitatif interpretatif dan interdisiplin. Menurut Tjetjep Rohendi (2011), kajian interdisiplin menghasilkan teori- teori yang relevan dengan, dan berguna bagi, pemecahan yang komprehensif terhadap masalah-masalah yang menjadi sasaran kajiannya, yang belum tentu dapat dihasilkan oleh kajian ilmiah untuk masalah kajian yang sama. Berikut ini adalah bagan pendekatan interdisiplin untuk penelitian ini yang dikembangkan berdasarkan gambar pendekatan interdisiplin Tjetjep Rohendi Rohidi:

\section{HASIL DAN PEMBAHASAN}

\section{A. Wacana Estetika dalam Kebudayaan Populer/ Budaya Massa}

Kitsch memiliki keterkaitan kuat dengan kebudayaan populer. Untuk memahami kitsch sebagai sebuah wacana estetika, ia mesti ditempatkan dalam konteks budaya 


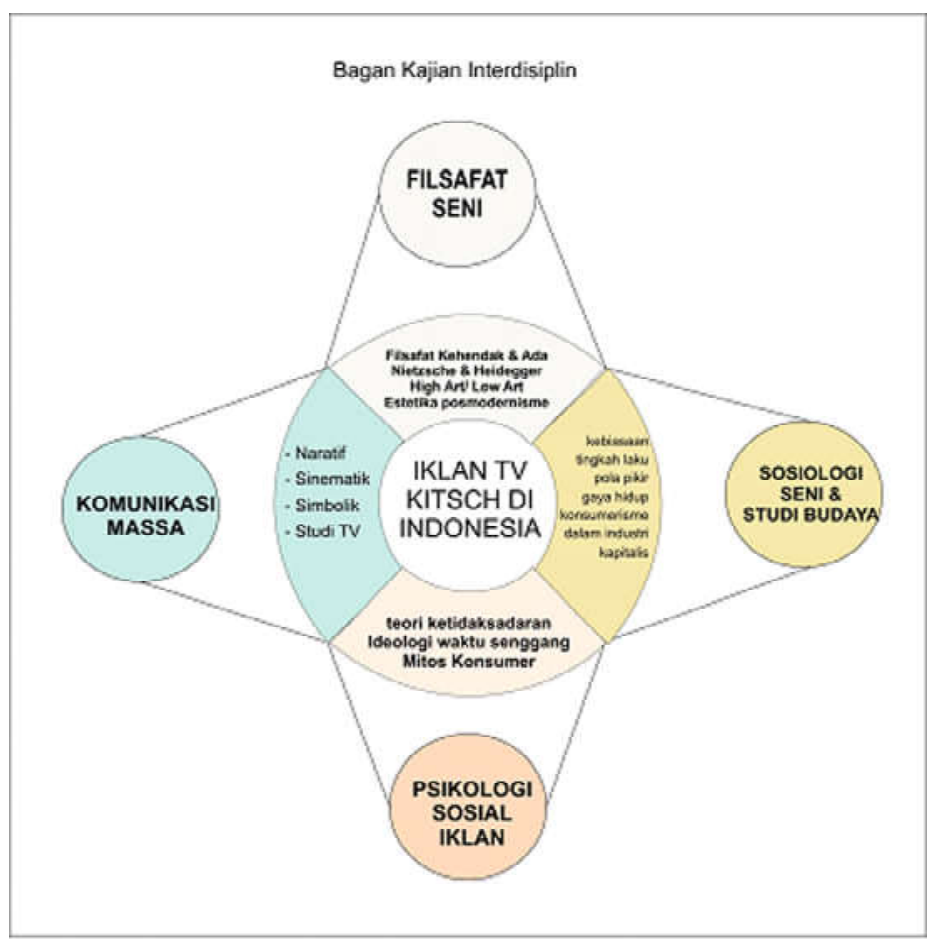

Gambar 1 .

Bagan kajian interdisiplin untuk meneliti Iklan TV bermuata kitsch di Indonesia, dan kaitannya dengan Selera Konsumer Indonesia (diadaptasi dari model kajian Interdisiplin Tjetjep Rohendi Rohidi, 2011:hal 66)

massa dan industrialisasi. Salah satu figur penting dalam perdebatan mengenai kebudayaan massa menurut Yasraf Amir Piliang adalah Theodore Adorno, seorang Neo Marxis dari mazhab Frankfurt School. Adorno mengkritik budaya massa secara frontal yang dianggapnya sebagai “produk dari penafsiran kapitalisme yang keliru terhadap semangat pencerahan" (Piliang: 2012).

Yasraf (2012) menjelaskan bahwa "Pemikiran Adorno akan berhadapan dengan Neo Marxis lain, Walter Benjamin, dan lebih jauh lagi dengan para pemikir post- strukturalisme dan post modernisme semacam Deleuze, Derrida, Lyotard, dan Jean Baudrillard". Yasraf menerangkan:

"Walter Benjamin membuka peluang adanya reproduksi dalam seni, bahwa secara prinsipil setiap karya seni selalu dapat direproduksi. Benjamin tidak saja memberikan peluang bagi sejumlah besar orang untuk menikmati karya seni, akan tetapi juga dapat menantang status otonomi seni. Reproduksi dapat menanggalkan seni dari menara gading elit, dan menggelarnya di hadapan massa. Dengan statusnya yang baru, seni dapat menjadi suatu cara representasi - menjadi sebuah tanda". (Piliang: 2012)

Yasraf menjelaskan bahwa secara filosofis, sesungguhnya pertentangan antara seni tinggi dengan kebudayaan massa adalah refleksi dari pertarungan pemikiran antara tokoh- tokoh modernisme puritan dengan Hegel sebagai rajanya, berhadapan dengan tokoh- tokoh post- modernisme awal terutama Nietszche dan Heidegger". Menurut Yasraf, "konsep-konsep kunci nihilisme dan diferensi yang dikembangkan oleh Nietszche dan Heidegger - yang kemudian menjadi konsep kunci postmodernisme - merupakan suatu penyangkalan terhadap konsep dialektika 
Hegelian" (Piliang, 2012).

Nietzsche dalam karya fenomenalnya The Birth of Tragedy, melukiskan dua kecenderungan dalam seni dan kebudayaan Yunani, yakni kecenderungan Apollonian dan Dionyssian. Kecenderungan naluri Apollonian lebih tenang, simetris, sederhana, bijaksana, sedangkan naluri Dionyssian bersifat irasional, keras, riang naluri yang digairahkan oleh "obat narkotik yang darinya semua bangsa primitif mengumandangkan hymne mereka" (Nietzsche,1956). Dionysos, menurut Nietzsche merupakan "simbol dari peleburan manusia dengan 'jantungnya dunia', yakni Will, Kehendak, atau Ada". Bagi Nietzche, "menyatunya subjek dengan Ada, merupakan prakondisi lenyapnya subjek yang berkuasa dalam versi modernitas, yakni subjek sebagai pusat akal budi. Subjek bukanlah sesuatu yang dapat menentukan landasan wacananya sendiri, akan tetapi subjek yang terus hidup dalam bayang- bayang Ada" (Nietzsche dalam Piliang: 2011). Dionysos mengembalikan apa yang dihapus oleh modernisme, yakni mitos, yang dalam pemikiran modernisme harus dibuang jauh- jauh karena ketidakrasionalannya.

Menurut Nietzsche, sesuatu yang jelek dan sumbang sekalipun merupakan sebuah permainan bahasa estetik, ketika kehendak (will) berada dalam puncak keriangannya, bermain dengan dirinya sendiri" (Piliang:2011).

Dalam kaitan dengan permainan bahasa estetik semacam inilah, seseorang atau suatu kelompok masyarakat tertentu yang memiliki gaya dan selera estetis yang khas, tidak dapat dihukumi atau dijustifikasi sebagai suatu bentuk kerendahan seni, atau diejek sebagai orangorang yang memiliki selera rendahan. Dikotomi seni rendah/ seni tinggi menjadi lebur dan tidak lagi memiliki kekuatan dalam wacana estetika post-modernisme.

Budaya populer, iklan, dan industri pertelevisian sekarang ini bahkan sanggup menggantikan posisi seni modern dalam fenomena gaya estetis dan selera masyarakat. Kitsch, sebagai suatu ungkapan estetika post modern, memiliki tempat yang sejajar dengan gaya seni apapun yang berhak muncul sekarang ini dalam wujud karya apapun, dan dibuat oleh siapapun.

\section{B. Analisis Iklan TV Komersial yang Memiliki Muatan Kitsch}

Penelitian mengenai muatan kitsch yang terdapat dalam sebuah karya, termasuk iklan TV, meniscayakan terjadinya identifikasi dan kategorisasi berdasarkan intensitas pengaruh elemen- elemen kitsch yakni sensualitas, vulgaritas, provokasi, simulasi, repetisi, demitosisasi, dan stereotype, yang hinggap atau melekat di dalam iklan. Semakin banyak elemen- elemen tersebut terdapat dalam satu iklan, maka iklan tersebut makin dianggap kitsch".

Apabila dikaitkan dengan iklan produk komersil di layar TV sebagai sebuah manifestasi visual, kitsch di dalam iklan TV merupakan sebuah gaya ungkap audio visual yang direproduksi secara amat efektif, karena tujuan kitsch memang menghimbau dan menarik perhatian massa sebanyak mungkin. Dan medium televisi merupakan alat yang tepat untuk melipatgandakan tujuan tersebut.

Sifat kitsch sendiri menurut Clement Greenberg (1939), Gillo Dorfles (1969), Umberto Eco (1989), Jean Baudrillard (1990), J.H. Cillers (2008), dan Yasraf Amir Piliang (2011), "sama-sama ditandai dengan adanya unsur-unsur provokasi, simulasi, repetisi, keganjilan, yang berfungsi untuk meredupkan aura dari seni tinggi atau objek mitos yang diambilnya (demitosisasi) dan 
mengubahnya menjadi stereotype yang bertujuan untuk menggaet massa secepat dan sebanyak mungkin".

Penelitian mengenai muatan kitsch yang terdapat dalam sebuah karya, termasuk iklan TV, meniscayakan terjadinya identifikasi dan kategorisasi berdasarkan intensitas pengaruh elemen- elemen kitsch yakni sensualitas, vulgaritas, provokasi, simulasi, repetisi, demitosisasi, dan stereotype, yang hinggap atau melekat di dalam iklan. Semakin banyak elemen- elemen tersebut terdapat dalam satu iklan, maka iklan tersebut makin dianggap kitsch" (Hanif dkk, 2015).

Untuk menjelaskan bagaimana elemenelemen kitsch seperti provokasi, simulasi, adaptasi, keganjilan, repetisi, dipakai dalam iklan TV, penelitian ini mencoba menganalisis visualisasi adegan, narasi/ suara baik bersifat monolog, dialog, ataupun lirik lagu iklan, pengambilan sudut kamera, dan indikasi adanya elemen kitsch dari Iklan "Biji Selasih" dari PT Bintang Toedjoe, yang ditayangkan pada rentang bulan September 2015. Kajian ini diadaptasi dari semiotika komunikasi periklanan yang peneliti olah berdasarkan semiotika komunikasi dari Alex Sobur (2013), semiotika iklan dari Arthur Asa Berger (2000), dan Mitologi Roland Barthes (1993), yang disesuaikan dengan karakteristik iklan TV yang diteliti. Hasilnya adalah sebagai berikut:

Tabel 1.

Analisis Elemen Kitsch pada Iklan TV serbuk minuman “Biji Selasih Panas Dalam Bintang Toedjoe”

\begin{tabular}{|c|c|c|c|c|c|c|}
\hline No. & $\begin{array}{c}\text { Ciplikan Adegan/ } \\
\text { Visualisasi }\end{array}$ & Narasi/Suara & Teks & $\begin{array}{l}\text { Sudut } \\
\text { Kamera }\end{array}$ & Durasi & $\begin{array}{c}\text { Indikasi/Indeks } \\
\text { Kitsch }\end{array}$ \\
\hline 1. & & & & $\begin{array}{l}\text { Extreme } \\
\text { Long Shot } \\
(E L S)\end{array}$ & 1 detik & $\begin{array}{l}\text { Simulasi Danau } \\
\text { Buatan dan } \\
\text { Kapal Layar } \\
\text { Tiruan, mitos } \\
\text { wisata modern }\end{array}$ \\
\hline 2. & & $\begin{array}{l}\text { Monolog: } \\
\text { "Sariawaan !..." }\end{array}$ & & $\begin{array}{l}\text { Close Up } \\
(\mathrm{CU})\end{array}$ & 1 detik & $\begin{array}{l}\text { Provokasi } \\
\text { dengan suara } \\
\text { dan mimik } \\
\text { wajah } \\
\text { berlebihan }\end{array}$ \\
\hline 3. & & $\begin{array}{l}\text { Monolog: } \\
\text { "Bibir Pecaah } \\
\text { !.." }\end{array}$ & & $\begin{array}{l}\text { Close Up } \\
(\mathrm{CU})\end{array}$ & 1 detik & $\begin{array}{l}\text { Provokasi } \\
\text { dengan suara } \\
\text { dan mimik } \\
\text { wajah } \\
\text { berlebihan }\end{array}$ \\
\hline 4. & & $\begin{array}{l}\text { Monolog: } \\
\text { “ Panas Dalaam } \\
\text { !.." }\end{array}$ & & $\begin{array}{l}\text { Close Up } \\
(C U)\end{array}$ & 1 detik & $\begin{array}{l}\text { Provokasi } \\
\text { dengan suara } \\
\text { dan mimik } \\
\text { wajah } \\
\text { berlebihan }\end{array}$ \\
\hline 5. & & $\begin{array}{l}\text { Dialog: } \\
\text { "Gimanaa..?" }\end{array}$ & & $\begin{array}{l}\text { Medium } \\
\text { Close Up } \\
\text { (MCU) }\end{array}$ & & $\begin{array}{l}\text { Provokasi } \\
\text { dengan suara } \\
\text { dan mimik } \\
\text { wajah } \\
\text { berlebihan }\end{array}$ \\
\hline
\end{tabular}




\begin{tabular}{|c|c|c|c|c|c|c|}
\hline No. & $\begin{array}{c}\text { Ciplikan Adegan/ } \\
\text { Visualisasi }\end{array}$ & Narasi/Suara & Teks & $\begin{array}{l}\text { Sudut } \\
\text { Kamera }\end{array}$ & Durasi & $\begin{array}{c}\text { Indikasi/Indeks } \\
\text { Kitsch }\end{array}$ \\
\hline 6. & & $\begin{array}{l}\text { Dialog:"Butuh } \\
\text { Biji Tuuh!.. }\end{array}$ & & $\begin{array}{l}\text { Medium } \\
\text { Shot (MS) }\end{array}$ & 1 detik & $\begin{array}{l}\text { Provokasi } \\
\text { dengan Suara } \\
\text { merayu dan } \\
\text { kerlingan } \\
\text { menggoda. } \\
\text { Mitos Barat } \\
\text { Dongeng Putri } \\
\text { Duyung }\end{array}$ \\
\hline 7. & & Dialog:"'Haah.Biij?. & & $\begin{array}{l}\text { Medium } \\
\text { Shot (MS) }\end{array}$ & 1 detik & $\begin{array}{l}\text { Provokasi } \\
\text { dengan suara } \\
\text { dan mimik } \\
\text { wajah } \\
\text { berlebihan }\end{array}$ \\
\hline 8. & & $\begin{array}{l}\text { Narasi:"Baru..!"' } \\
\text { Bintang Tujuh }\end{array}$ & & $\begin{array}{l}\text { Medium } \\
\text { Close Up } \\
\text { (MCU) }\end{array}$ & 1 detik & $\begin{array}{l}\text { Provokasi } \\
\text { dengan kata- } \\
\text { kata promotif }\end{array}$ \\
\hline 9. & & $\begin{array}{l}\text { Narasi:Panas } \\
\text { Dalam, dengan } \\
\text { Biji Selasih.. }\end{array}$ & & $\begin{array}{l}\text { Medium } \\
\text { Long Shot } \\
(M L S)\end{array}$ & 1 detik & $\begin{array}{l}\text { Objek \& } \\
\text { Adegan ganjil/ } \\
\text { irasional, } \\
\text { orang } \\
\text { mengangguk- } \\
\text { anggukkan } \\
\text { kepala pada } \\
\text { Jeruk Nipis dan } \\
\text { Daun Selasih. } \\
\text { Adaptasi dan } \\
\text { simulasi } \\
\text { kepatuhan }\end{array}$ \\
\hline 10. & & $\begin{array}{l}\text { Narasi:Panas } \\
\text { Dalam... } \\
\text { Hilaaang ...!! }\end{array}$ & $\begin{array}{l}\text { Tulisan: } \\
\text { Biji } \\
\text { Selasih }\end{array}$ & $\begin{array}{l}\text { Medium } \\
\text { Long Shot } \\
\text { (MLS) }\end{array}$ & & $\begin{array}{l}\text { Objek \& } \\
\text { Adegan ganjil/ } \\
\text { irasional, Jeruk } \\
\text { Nipis dan } \\
\text { Daun Selasih } \\
\text { beterbangan di } \\
\text { dalam air }\end{array}$ \\
\hline 11. & & $\begin{array}{l}\text { Lagu: "Kalau } \\
\text { Panas Dalam.. }\end{array}$ & & $\begin{array}{l}\text { Long Shot } \\
\text { (LS) }\end{array}$ & & $\begin{array}{l}\text { Provokasi, } \\
\text { tiba- tiba ada } \\
\text { grup musik } \\
\text { dengan penari } \\
\text { yang muncul } \\
\text { dari sebuah } \\
\text { kotak, adaptasi } \\
\text { mitos barat } \\
\text { tentang wanita } \\
\text { penghibur } \\
\text { sebagai } \\
\text { "hadiah" }\end{array}$ \\
\hline
\end{tabular}




\begin{tabular}{|c|c|c|c|c|c|c|}
\hline No. & $\begin{array}{c}\text { Ciplikan Adegan/ } \\
\text { Visualisasi }\end{array}$ & Narasi/Suara & Teks & $\begin{array}{l}\text { Sudut } \\
\text { Kamera }\end{array}$ & Durasi & $\begin{array}{c}\text { Indikasi/Indeks } \\
\text { Kitsch }\end{array}$ \\
\hline 12. & & Катu Butuh & & $\begin{array}{l}\text { Tracking } \\
\text { Medium } \\
\text { Shot }\end{array}$ & 1 detik & $\begin{array}{l}\text { Provokasi } \\
\text { Simulasi } \\
\text { kegiatan } \\
\text { sehari- hari, } \\
\text { minum obat }\end{array}$ \\
\hline 13. & & Bijii... & & $\begin{array}{l}\text { Medium } \\
\text { Close Up } \\
\text { (MLS) }\end{array}$ & 1 detik & $\begin{array}{l}\text { Provokasi, } \\
\text { mimik wajah } \\
\text { dan mulut } \\
\text { yang } \\
\text { berlebihan } \\
\text { setelah minum }\end{array}$ \\
\hline 14 & & $\begin{array}{l}\text { (Air } \\
\text { Menyembur..) }\end{array}$ & & $\begin{array}{l}\text { Medium } \\
\text { Shot (MS) }\end{array}$ & 1 detik & $\begin{array}{l}\text { Objek \& } \\
\text { Adegan ganjil/ } \\
\text { irasionalTiba- } \\
\text { tiba muncul } \\
\text { semburan air } \\
\text { dari bawah } \\
\text { (Konotasi } \\
\text { seksual ?). } \\
\text { Kostum Pelaut } \\
\text { berubah lebih } \\
\text { cerah. }\end{array}$ \\
\hline 15. & & $\begin{array}{l}\text { "Bijinya } \\
\text { Selasiih... }\end{array}$ & & $\begin{array}{l}\text { Long Shot } \\
\text { (LS) }\end{array}$ & 1 detik & $\begin{array}{l}\text { Simulasi mitos } \\
\text { keseharian, } \\
\text { joged sambil } \\
\text { bernyanyi }\end{array}$ \\
\hline 16. & & "Panas Dalam.. & & $\begin{array}{l}\text { Medium } \\
\text { Close Up } \\
(\mathrm{MCU})\end{array}$ & 1 detik & $\begin{array}{l}\text { Simulasi dan } \\
\text { provokasi } \\
\text { dengan mimik } \\
\text { wajah } \\
\text { berlebihan dan } \\
\text { menggoda }\end{array}$ \\
\hline 17. & & Hilaang...! & & $\begin{array}{l}\text { Medium } \\
\text { Close Up } \\
(M C U)\end{array}$ & 1 detik & $\begin{array}{l}\text { Simulasi dan } \\
\text { provokasi } \\
\text { dengan mimik } \\
\text { wajah } \\
\text { berlebihan dan } \\
\text { menggoda }\end{array}$ \\
\hline
\end{tabular}




\begin{tabular}{|c|c|c|c|c|c|c|}
\hline No. & $\begin{array}{c}\text { Ciplikan Adegan/ } \\
\text { Visualisasi }\end{array}$ & Narasi/Suara & Teks & $\begin{array}{l}\text { Sudut } \\
\text { Kamera }\end{array}$ & Durasi & $\begin{array}{c}\text { Indikasi/Indeks } \\
\text { Kitsch }\end{array}$ \\
\hline 18. & & $\begin{array}{l}\text { (musik } \\
\text { menghentak- } \\
\text { hentak) }\end{array}$ & & $\begin{array}{l}\text { Medium } \\
\text { Close Up } \\
\text { (MCU) }\end{array}$ & 1 detik & $\begin{array}{l}\text { Objek \& } \\
\text { Adegan ganjil/ } \\
\text { irasional. } \\
\text { Suara beat } \\
\text { musik dikuiti } \\
\text { serentak } \\
\text { dengan } \\
\text { gambar penari } \\
\text { berpakaian } \\
\text { seksi yang } \\
\text { hilang-muncul } \\
\text { beberapa kali }\end{array}$ \\
\hline 19. & & $\begin{array}{l}\text { Lagu terus } \\
\text { berlanjut: “Ayo } \\
\text { Goyang Biji... }\end{array}$ & & Close Up & 1 detik & $\begin{array}{l}\text { Provokasi } \\
\text { dengan kalimat } \\
\text { persuasif dan } \\
\text { mitos lagu } \\
\text { dangdut } \\
\text { populer } \\
\text { "Goyang } \\
\text { Dumang" yang } \\
\text { diganti } \\
\text { liriknya }\end{array}$ \\
\hline 20 & & “Кати.... & & $\begin{array}{l}\text { Close Up } \\
\text { (CU) }\end{array}$ & 1 detik & $\begin{array}{l}\text { Simulasi dan } \\
\text { provokasi } \\
\text { dengan mimik } \\
\text { wajah dan } \\
\text { gestur } \\
\text { menggoda }\end{array}$ \\
\hline 21. & & "Butuh Biji.." & & $\begin{array}{l}\text { Long Shot } \\
\text { (LS) }\end{array}$ & 1 detik & $\begin{array}{l}\text { Simulasi mitos } \\
\text { keseharian, } \\
\text { joged sambil } \\
\text { bernyanyi }\end{array}$ \\
\hline 22. & & "Bijinya.. & & $\begin{array}{l}\text { Medium } \\
\text { Shot (MS) }\end{array}$ & 1 detik & $\begin{array}{l}\text { Simulasi dan } \\
\text { provokasi } \\
\text { dengan mimik } \\
\text { wajah dan } \\
\text { gestur joged/ } \\
\text { goyangan } \\
\text { tubuh yang } \\
\text { menggoda }\end{array}$ \\
\hline 23. & & "Selasih... & & $\begin{array}{l}\text { Long Shot } \\
\text { (LS) }\end{array}$ & 1 detik & $\begin{array}{l}\text { Simulasi mitos } \\
\text { keseharian, } \\
\text { joged sambil } \\
\text { bernyanyi }\end{array}$ \\
\hline
\end{tabular}




\begin{tabular}{|c|c|c|c|c|c|c|}
\hline No. & $\begin{array}{c}\text { Ciplikan Adegan/ } \\
\text { Visualisasi }\end{array}$ & Narasi/Suara & Teks & $\begin{array}{l}\text { Sudut } \\
\text { Kamera }\end{array}$ & Durasi & $\begin{array}{c}\text { Indikasi/Indeks } \\
\text { Kitsch }\end{array}$ \\
\hline 24 & & "Bintang... & & $\begin{array}{l}\text { Medium } \\
\text { Shot (MS) }\end{array}$ & 1 detik & $\begin{array}{l}\text { Simulasi dan } \\
\text { provokasi } \\
\text { dengan mimik } \\
\text { wajah dan } \\
\text { gestur joged/ } \\
\text { goyangan } \\
\text { tubuh yang } \\
\text { menggoda }\end{array}$ \\
\hline 25. & & Tujuuh..." & & $\begin{array}{l}\text { Long Shot } \\
\text { (LS) }\end{array}$ & 1 detik & $\begin{array}{l}\text { Simulasi mitos } \\
\text { keseharian, } \\
\text { joged sambil } \\
\text { bernyanyi }\end{array}$ \\
\hline 26. & & $\begin{array}{l}\text { Monolog: } \\
\text { "BIJINYA } \\
\text { DIGOYANG..." }\end{array}$ & & $\begin{array}{l}\text { Medium } \\
\text { Shot (MS) }\end{array}$ & 1 detik & $\begin{array}{l}\text { Provokasi } \\
\text { dengan } \\
\text { memakai } \\
\text { Mitos artis } \\
\text { dangdut } \\
\text { wanita seksi } \\
\text { menggoda } \\
\text { dengan mimik } \\
\text { wajah dan } \\
\text { kata- kata. } \\
\text { yang } \\
\text { mengandung } \\
\text { polisemi } \\
\text { makna } \\
\text { berkonotasi } \\
\text { seksual. }\end{array}$ \\
\hline 27. & a & $\begin{array}{l}\text { Monolog: } \\
\text { "PANAS } \\
\text { DALAM } \\
\text { HILANG..." }\end{array}$ & & $\begin{array}{l}\text { Medium } \\
\text { Shot (MS) }\end{array}$ & 1 detik & $\begin{array}{l}\text { Provokasi } \\
\text { dengan } \\
\text { memakai } \\
\text { Mitos artis } \\
\text { dangdut } \\
\text { wanita seksi } \\
\text { menggoda } \\
\text { dengan mimik } \\
\text { wajah dan } \\
\text { kata- kata } \\
\text { promotif. }\end{array}$ \\
\hline
\end{tabular}

Sumber:(www.mufiza.net._iklan_terbaru_Cita_Citata_dan_Trio_Ubur_Ubur_Minuman_Panas_Dalam) diunggah $27 \overline{\text { Maret }} 2015$ Pukul $22.4 \overline{0}$ 
Berdasarkan analisis elemen kitsch pada iklan "Biji Selasih Bintang Toedjoe" di atas, muatan kitsch pada iklan TV tersebut merupakan perpaduan atau hibriditas dari mitos barat modern seperti wisata kapal pesiar, wanita penghibur, pelaut yang bertemu puteri duyung, serta mitos keseharian masyarakat Indonesia, seperti bernyanyi dan bergoyang bersama diiringi lagu dan musik serta artis dangdut wanita dengan mimik wajah dan gestur yang menggoda. Dengan melihat campuran antara mitos barat modern yang biasa dikaitkan dengan selera kelas menengah/ menengah atas, dicampurkan dengan mitos asli Indonesia seperti goyang dan lagu dangdut, maka peneliti menyimpulkan bahwa sasaran iklan yang dianggap bermuatan kitsch tersebut adalah masyarakat kelas menengah dan menengah ke bawah (kelas B-C) dengan sifat, perilaku, dan kebudayaan tertentu yang khas, yang memiliki cara pandang tertentu terhadap sebuah benda konsumsi yang diiklankan di televisi.

Cara pandang konsumen ini bisa dipengaruhi oleh berbagai hal, misalnya: mitos tertentu (legenda puteri duyung bertemu dengan para pelaut, mitos batu akik), agama dan keyakinan tertentu (Islam, Kristen, Hindu, Budha), kebudayaan lokal tertentu (tari dan kesenian jawa, ekspresi dan gaya tubuh, humor dan canda), atau budaya visual yang selama ini ditangkap oleh mereka baik lewat pendidikan keluarga, sekolah, maupun media komunikasi massa seperti artis dan lagu dangdut atau sinetron yang sedang populer. Ironisnya, hal ini berarti semakin mengekalkan pendapat bahwa ideologi kapitalisme masih menjadi pemenang dalam mengatur kehidupan sosial budaya dan ekonomi masyarakat Indonesia, dan mitos modern bahwa konsumer selalu terkelabui/ tertipu oleh gagasan palsu dari periklanan modern, memang benar adanya (Hanif dkk, 2015).

Meskipun demikian, dari sisi selera massa, pandangan tersebut belum tentu difahami sebagai sesuatu yang negatif. Khalayak konsumer tetap memiliki pilihan untuk tidak membeli produk yang diiklankan. Dan kesenangan ketika menonton tayangan iklan, harus dipisahkan terlebih dahulu dengan tindakan membeli produk. Penonton tidak serta merta mengikuti perintah iklan untuk mengkonsumsi produk, walaupun hal tersebut masih harus diteliti dengan seksama. Barangkali penonton kelas menengah dan menengah bawah tersebut hanya ingin melepaskan kepenatan dan rasa lelah setelah seharian bekerja keras membanting tulang. Mereka hanya butuh hiburan sesaat dengan menikmati iklan- iklan bermuatan kitsch.

Program tayangan yang sensasional akan menarik para pengiklan dengan iklaniklannya yang juga provokatif dan sensasional, dan iklan tersebut akan menarik minat massa konsumer yang tidak kritis sebanyak mungkin. Iklan TV komersial merupakan nafas dari industri pertelevisian untuk dapat bertahan hidup. Meskipun demikian, tidak berarti materi iklan produk bisa ditayangkan sebebasbebasnya seperti di berbagai negara maju yang terang- terangan menganut demokrasi liberal. Indonesia memiliki aturan dan etika untuk menayangkan iklan produk di stasiun televisi, yang disesuaikan dengan kondisi sosio-kultural masyarakatnya, meski hal inipun menjadi sebuah paradoks yang kontradiktif.

Kasus yang menarik dari iklan TV produk serbuk minuman pereda panas dalam "Biji Selasih" dari Bintang Toedjoe (tayang bulan Juni 2015 sebelum Bulan Ramadhan), yang secara kebetulan 
termasuk pada iklan bermuatan 'kitsch', diprotes oleh sebagian masyarakat karena kalimat 'bijinya digoyang' yang diucapkan oleh artis Cita Citata, berkonotasi seksual. Kalimat 'bijinya digoyang' akhirnya diganti menjadi 'selasihnya digoyang', dan ditayangkan selama Bulan Ramadhan. Dan satu hal yang menarik, setelah bulan Ramadhan 2015 berlalu, Iklan tersebut kembali ditayangkan dalam edisi awal, yang memakai kalimat 'bijinya digoyang'.

Pada kasus iklan TV tersebut tampak jelas ciri manusia Indonesia menurut Mochtar Lubis (1992), yakni suka pamer, percaya tahayul (mitos puteri duyung), artistik, punya rasa humor, dan bisa tertawa dalam penderitaan, namun terkadang hipokrit. Di satu sisi seolah tidak setuju dengan tayangan iklan yang menonjolkan sensualitas, di sisi lain, demi kepentingan bisnis, iklan dapat ditayangkan kembali dengan beberapa catatan yang disesuaikan dengan situasi dan kondisi. Budaya 'basa- basi' yang bersifat paradoks seperti ini barangkali hanya dimiliki oleh manusia Indonesia.

\section{SIMPULAN}

Selera konsumer Indonesia yang kitsch , adalah kesenangan mereka terhadap segala sesuatu yang mampu menarik perhatian mereka seketika, misalnya pakaian dengan corak dan warna yang mencolok, make up yang tebal, asesoris dan perhiasan yang murah namun terlihat mewah, ekspresi wajah yang berlebihan dan bahasa tubuh yang sensual atau menggoda. Kitschizen Indonesia juga menyukai lagu dan artis yang sedang populer, terutama lagu dengan irama dangdut yang dinyanyikan oleh artis wanita yang cantik dan seksi. Kitschizen Indonesia juga sangat menyenangi adegan humor yang bisa membuat mereka tertawa dan terhibur walau hidupnya penuh dengan beban masalah.
Mitos, legenda, takhayul, juga menjadi sesuatu yang menyenangkan bagi masyarakat konsumer Indonesia, dalam arti mereka senang menonton suatu acara yang membicarakan makhluk gaib, jin, dongeng rakyat, hantu (jurig, genderuwo), dll. Mereka menghargai sebuah karya seni bukan karena aspek estetis dan apalagi originalitasnya, namun karena melihat daya tarik warna, bentuk, objek, ataupun kemasan yang provokatif dari karya tersebut.

Cerita dan pesan dari Iklan TV bermuatan kitsch adalah refleksi dari selera mereka. Sebaliknya, selera mereka juga dipengaruhi oleh iklan TV bermuatan kitsch tersebut. Cerita yang diambil dari mitos puteri duyung di Eropa dicampurkan dan diramu sedemikian rupa dengan mitos modern khas Indonesia, yakni penyanyi dangdut wanita dengan lagu yang sedang populer untuk menarik perhatian pemirsa dan menaikkan angka penjualan. Hal ini menjadi semacam hibriditas yang khas dalam iklan TV tersebut.

Kesimpulan ini semakin mengukuhkan bahwa iklan bermuatan kitsch merupakan sebuah alat ampuh yang sangat efektif, yang memiliki kode-kode yang dibuat sedemikian rupa, untuk merayu dan membujuk pemirsanya dengan cara yang vulgar dan provokatif.

\section{Daftar Pustaka}

Alex Sobur

2013 Semiotika Komunikasi, Bandung, PT Remaja Rosda Karya

Barthes, Roland

1991 Mythologies, New York: The Noonday Press - New York Farrar, Straus \& Giroux

Baudrillard, Jean

1981 For a Critique of the Political Economy of The Sign, Telos Press 
1990 Revenge of The Crystal, Pluto Press

Berger, Arthur Asa

2000 Tanda-tanda dalam Kebudayaan Kontemporer, Penerjemah M. Dwi Marianto dan Sunarto, Yogyakarta, Tiara Wacana

Cilliers, John

2000 The Unveiling of Life: Liturgy and the Lure of Kitsch, HTS Teologiese Studies/Theological Studies66(2), Art. \#815

Dorfles, Gillo

1970 The Antology of Bad Taste, London, Studio Vista-Universe Book

Eco, Umberto

1989 The Structure of Bad Taste, dalam The Open Work, Hutchinson Radius

Muchtar Lubis

1992 Budaya, Masyarakat, Dan Manusia Indonesia, Jakarta: Yayasan Obor Indonesia

Macrury, Iain

2002 Advertising, Routledge

Nietszche, Friedrich

1956 The Birth of Tragedy, New York: A Double Day Anchor Book

Rather, Dan., Isaacson, Walter

1999 People of The Century, 100 man and women who shapes the last 100 years, Time/ CBS News

Scott, Walter Dill

1921 The psychology of advertising in theory and practice: a simple exposition of the principles of psychology in their relation to successful advertising. Maynard: Small
Syaiful Halim

2013 Postkomodifikasi Media, Analisis Media Televisi dengan Teori Kritis dan Cultural Studies, Yogyakarta: Jalasutra

Tjetjep Rohendi Rohidi

2011 Metode Penelitian Seni, Semarang: Penerbit Citra Nuansa

Wildan Hanif, Yasraf A.Piliang, Agung Eko Budi Waspada

2015 Indonesian Kitsch in Year 2015, from Philosophical Concept to Product and Consumer Behaviour", Tanjong Malim, Malaysia: Publikasi Seminar Internasional "Nusantara Herritage 3, Universitas Pendidikan Sultan Idris,

2015 "Sensualitas Kitsch pada Iklan TV Komersial 'Biji Selasih Bintang Toedjoe', Univ. Maranatha Bandung: publikasi seminar nasional, DISC Maranatha

Yasraf Amir Piliang

2011 Bayang-bayang Tuhan: Agama dan Imajinasi, Bandung: Mizan Publika

2012 Semiotika dan Hipersemiotika, kode, gaya, dan matinya makna, Bandung: Penerbit Matahari 